\title{
Conflicts of Interest Result From Relationships But Are Not Resolved by Preventing Relationships
}

\author{
Carlo Petrini $[$ - Luciana Riva
}

Received: 7 August 2020 / Accepted: 23 December 2020 /Published online: 6 January 2021

(C) Journal of Bioethical Inquiry Pty Ltd. 2021

\begin{abstract}
Goldberg notes that the relationship is a component of Conflicts of Interests (COIs). Networks of relationships and the simultaneous presence of several interests are not negative per se but become so when they generate a conflict that undermines impartiality. The solution to the problem of COIs, therefore, cannot be to abolish relationships and the interests that they necessarily express but rather to verify whether those relationships are such as to unduly affect an individual's judgement. The evolution of an Italian legislation about COIs is eloquent in this regard.
\end{abstract}

Keywords Bioethics $\cdot$ Clinical Trials $\cdot$ Conflicts of Interests $\cdot$ Legislation

The symposium on conflicts of interests convened by the Journal of Bioethical Inquiry provides a number of interesting discussion points

Goldberg argues in depth that financial Conflicts of Interests (fCOIs) are of higher ethical priority than "intellectual" Conflicts of Interest (iCOIs), on the basis of two considerations (Goldberg 2020, 222):

1) "COIs flowing from our relationships with people (or groups of people) are more important than COIs

\footnotetext{
C. Petrini $(\bowtie) \cdot$ L. Riva

Bioethics Unit, Istituto Superiore di Sanità (Italian National Health Institute), Via Giano della Bella 34, 00162 Rome, Italy

e-mail: carlo.petrini@iss.it

e-mail: luciana.riva@iss.it
}

flowing from intellectual commitments because the former dramatically impact trust in a social role. The latter do not or do so to a lesser extent".

2) "fCOIs are eliminable and iCOIs are not. (This is not a strong argument for denying the existence or impact of iCOIs. It is a much more plausible argument when put in service of a priority-setting claim)".

Goldberg also notes that "it is the relationship between particular parties that roots and grounds motivated bias and the increased risk of behaviour of partiality that ensues" (Goldberg 2020, 219).

The relationship is a component of the COI, but, as Goldberg asserts, we must recognize that "relationships bind us together, promote social cohesion, and are fundamental to life in virtually any primate society" (Goldberg 2020, 219). In particular, relationships are essential in research, if such research is to be valid and of value.

The presence of networks of relationships and the simultaneous presence of several interests are not negative per se but become so at the point when they generate a conflict that undermines impartiality.

The solution to the problem of COIs, therefore, cannot be to abolish relationships and the interests that they necessarily express but rather to verify whether those relationships are such as to unduly affect an individual's judgement.

Legislative Decree No 52 of 14 May 2019 (President of the Italian Republic 2019) is important in terms of the possible consequences of relationships in Italy. The Decree was adopted as the result of a law promulgated in 2018 laying down certain guidelines for clinical trials. 
In relation to conflicts of interest, the initial wording of the Decree required the following (Article 6(4)):

... the absence, in relation to the proposed study, of individual financial interests or those of spouses or partners or relations up to the second degree in the capital of the pharmaceutical company owning the drug covered by the study, and the absence of employment, consultancy or collaborative relationships, in any guise, with the promotor.

The wording was therefore very restrictive. For example:

- it prevents financial interests of "relations up to the second degree", and it can be difficult to verify whether a cousin, with whom one might only have rare contact, has investments in a fund and shares in a pharmaceutical company;

- it prevents an employee of a hospital from taking part in a clinical trial promoted by that hospital.

In particular, the text is restrictive in that it also prevents any "collaborative" relationships between the researcher and the promotor, without making a distinction between financial and non-financial interests. For some months, there has been considerable difficulty in Italy in implementing new clinical trials, and various methods have been used to seek to address the problem: for example, in some situations in which all of the researchers have had relationships with the promoter, even where these are very remote, young university students have been indicated as investigators.

As part of the legal texts adopted in Italy to manage the COVID-19 emergency (Italian Parliament 2020), an amendment has been approved rewording Article 6(4) of Legislative Decree No 52 of 14 May 2019 and stipulating that investigators must declare in advance to the facility conducting the clinical study

... their financial interests or those of their spouses or partners or relations up to the second degree in relation to the proposed study, and employment, consultancy or collaborative relationships, in any guise, with the promotor, in any phase of the study, that are established. The ethics committee will evaluate that declaration and the absence of shareholdings in the capital of the pharmaceutical company owning the drug covered by the study on the part of the investigators or their spouses or partners, as a safeguard for the independence and impartiality of the clinical trial, even after the study has commenced, where new conflicts of interest arise.

The new wording does not therefore exclude a priori relationships or interests but rather requires a declaration that is evaluated by the ethics committee.

Thus, COIs can develop within relationships, but the solution certainly cannot be to prevent all relationships. Because relationships are complex, they must be assessed on a case-by-case basis, using criteria based on proportionality, transparency, accountability, fairness, and independence, and also considering the circumstances: the presence of diverse interests is unacceptable only where this could compromise the integrity of judgement. It is only at this point that they become fCOIs or iCOIs, and no longer merely legitimate interests and relationships.

\section{References}

Goldberg, D.S. 2020. Financial conflicts of interest are of higher ethical priority than "intellectual" conflicts of interest. Journal of Bioethical Inquiry 17(2): 217-227.

Italian Parliament. 2020 (17 July). Law No 77 of 17 July 2020. Conversion into law, with amendments, of Decree-Law No 34 of 19 May 2020, laying down urgent measures in relation to health and support for employment and the economy, and social policies in relation to the Covid-19 epidemiological emergency (with text of Decree-Law No 34 of 19 May 2020, coordinated with Conversion Law No 77 of 17 July 2020, on: 'Urgent measures in relation to health and support for employment and the economy, and social policies in relation to the Covid-19 epidemiological emergency'). Official Gazette of the Italian Republic - General Series No 180 (Ordinary Supplement No 25/L: 1-136.

President of the Italian Republic. 2019 (12 June). Legislative Decree No 52 of 14May 2019. Implementation of the delegation of authority to the Government to reorganise and reform the legal provisions relating to clinical trials on medicinal products for human use, in accordance with Article 1(1) and (2) of Law No 3 of 11 January 2018. Official Gazette of the Italian Republic - General Series No 136: 1-11.

Publisher's note Springer Nature remains neutral with regard to jurisdictional claims in published maps and institutional affiliations. 